\title{
Fine Motor Skills, Writing Skills and Physical Education Based Assistive Intervention Program in Children at Grade 1
}

\author{
Sinan Akin \\ Kütahya Dumlupınar University, School of Physical Education and Sports, Kütahya, Turkey. \\ Email:sinan.akin@dpu.edu.trTel: +905058245232
}

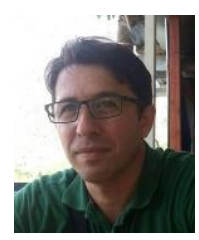

\begin{abstract}
The purpose of this study is to investigate the effect of physical education based intervention program, aiming to help the development of writing skills of primary school children, on fine motor skill precision and fine motor skill integration. A total of 104 primary school children at grade 1 with at least 2 years of preschool education participated in the study. Children in the experimental group, together with the curriculum studies, did adapted ball control drills three times a week, each 40 minutes, for 10 weeks. Fine motor skill levels of the children were examined with tests of Manual dexterity, Upper limb coordination, Fine motor skill precision and Fine motor skill integration sub-dimensions in the complete form of the Bruininks-Oseretsky test of Motor Proficiency Second Edition (BOT-2). The first measurement was made in the first week of school education, and the last measurements were made after a 10-week intervention period. Data were evaluated by repeated measures analysis of variance and simple effect test. At the end of the intervention, dexterity, upper extremity coordination, fine motor skill sensitivity and fine motor skill integration values improved in the experimental group compared to the control group. This difference between two groups was determined to be statistically significant. As a result, it can be said that physical education based intervention programs for small muscle groups positively affect children's fine motor skills development and thus their interest in writing and schooling.
\end{abstract}

Keywords: Fine motor skill, Fine motor integration, Fine motor precision, Handwriting, Manual dexterity, Physical education program, Primary school, Upper limb coordination, Bruiniks-oseretsky motor proficiency test-2.

Citation | Sinan Akin (2019). Fine Motor Skills, Writing Skills and Physical Education Based Assistive Intervention Program in Children at Grade 1. Asian Journal of Education and Training, 5(4): 518-525.

Received: 9 July 2019

Revised: 16 August 2019

Accepted: 26 September 2019

Published: 31 October 2019

Licensed: This work is licensed under a Creative Commons

Attribution 3.0 License (cc) Er

Publisher: Asian Online Journal Publishing Group
Funding: This study received no specific financial support.

Competing Interests: The author declares that there are no conflicts of interests regarding the publication of this paper.

Transparency: The author confirms that the manuscript is an honest, accurate, and transparent account of the study was reported; that no vital features of the study have been omitted; and that any discrepancies from the study as planned have been explained.

Ethical: This study follows all ethical practices during writing.

\section{Contents}

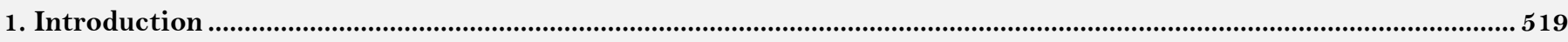

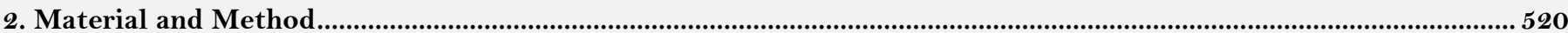

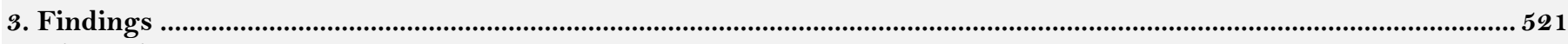

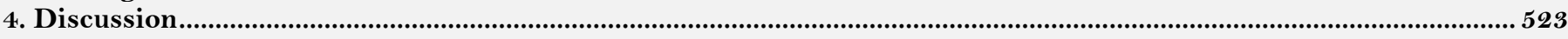

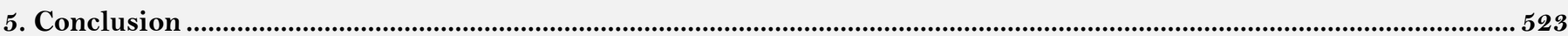

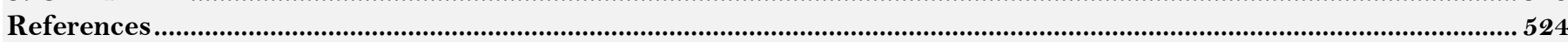




\section{Contribution of this paper to the literature}

This study contributes to existing literature by investigating the effect of physical education based intervention program, aiming to help the development of writing skills of primary school children, on fine motor skill precision and fine motor skill integration.

\section{Introduction}

Developmentally, a preschool child sharpens the visual perceptual and fine motor skills necessary to perform activities that require visual-motor integration, such as handwriting (Beery, 1997). Fine motor skills also play an important role in sustaining people's daily lives (Linde et al., 2013). Fine motor skill competence is an essential component of daily life activities. Poor fine motor skills can cause increased anxiety, distress in academic achievement and poor self-esteem (Gaul and Issartel, 2016).

The majority of the daily life of school-age children is spent at school and 30-60\% of this time is spent performing fine motor tasks (McHale and Cermak, 1992). Almost $85 \%$ of the time spent on fine motor tasks consists of paper and pencil-based activities, which are perhaps about the most important skills for academic achievement (Marr et al., 2003). It was found that children with strong fine motor skills showed earlier development in reading skills and higher academic achievement (Cameron et al., 2012).

Due to the development of technology, the amount of time children are exposed to technology products increases day by day (Lauricella et al., 2015) which limits the movement experiences necessary for children to continue their daily lives (Maitland et al., 2013). However, some studies have suggested that fine motor skills are not adversely affected because fine motor skills are required to use technological products (Adams et al., 2012). Nevertheless, these skills are forced to a different orbit, which leads to the loss of fine motor skills that an individual needs in daily life (Coll, 2015). Considering that an individual has to master the motor skills by the age of 10 (Gallahue et al., 2012) many fine skills may be considered at risk. It is stated that children with such motor impairment as Developmental Coordination Disorder (DCD) have difficulty in tying shoelaces, buttoning shirt button, opening and closing the zipper, brushing teeth and using cutlery (Wang et al., 2009; Magalhaes et al., 2011). Unfortunately, if intervention is not performed at the right time, these difficulties may continue throughout life and ultimately affect their quality of life (Gaul and Issartel, 2016).

Fine motor skills are the types of skills performed using small groups of muscles necessary to move objects (Gallahue et al., 2012). In addition, fine motor skills include graphomotor skills (GS) including the control and strength of the muscles (Levine, 1987). Fine Motor Skill represents a set of skills connected to a set of similar structures, such as hand-eye coordination, transformation of a visually perceived object into motor output, skills involved in writing, and even handwriting (Bart et al., 2007). However, in some studies, the definition of Fine Motor Skill has been expressed as "small muscle movements requiring close hand-eye coordination" (Suggate et al., 2019). Good motor skills can serve as a buffer for normative difficulties experienced by children in transition to school whereas poor motor skills emerge as a weakness in transition to primary school education (Bart et al., 2007).

The majority of school-age children display poor drawings and handwriting (Bingham and Snapp-Childs, 2019). Difficulties in handwriting skills among children of primary school age have been shown as one of the most common reasons for directing children to pediatric occupational therapy services worldwide (Feder et al., 2000). Weak fine motor control, lack of coordination in muscle contraction, irregularity in impact rate and strength can lead to distorted and illegible handwriting, and therefore, evaluation of fine motor control in handwriting movement is important in the comprehensive assessment of handwriting dysfunction. Clinical observations and performance tests are traditionally part of the handwriting evaluation (Rosenblum et al., 2003; Di Brina et al., 2008; Lam et al., 2011). Handwriting incompetency may be caused by inappropriate external factors such as biomechanical or environmental components, or internal factors such as poor performance in perceptual and motor skills.

Monitoring and drawing tasks are the prominent tools for evaluating various aspects of motor control. Therefore, many exemplary models designed to study motor control included them as part of their assessment (Smits et al., 2018). Factors such as visual perception show little correlation with handwriting, whereas tactile kinaesthetic, visual motor and motor planning are more closely related to handwriting (Tseng and Cermak, 1993). As well as handwriting, visual-motor coordination abilities, motor planning, cognitive and perceptual skills, a mix of tactile and kinaesthetic sensitivities are complex perceptual-motor skills (Maeland, 1992). Furthermore, handwriting appears as a perceptual motor skill acquired through repetitive practice (Feder and Majnemer, 2007) and is often presented as an example of motor skill acquired through procedural learning processes (Wilhelm et al., 2012). Handwriting is actually a very complex skill. A proper handwriting requires fine motor skills, visual perception, cognition integration and maturation (Volman et al., 2006; Shams and Kim, 2010). Therefore, fine motor skills are important because correctly formed letters can only be produced with force control and proper timing of coordinated finger, hand and arm movements (Alston and Taylor, 1987). There are many basic skill components that will interfere with handwriting performance. Before starting the handwriting process, children need to develop preparation skills to form letters, such as development of large and small muscles, visual perception, fine motor skills, and hand manipulation skills (Lamme, 1979). When copying letters and words, children need not only keeping the task in mind, attention, visual and manual coordination, but also control of fine movements and enough power of the finger and the hand (Stevenson and Just, 2014). It is seen that motor competence measures related to handwriting production have an indirect effect on handwriting in school age children (Berninger, 2009). Acquiring handwriting skills at the beginning of education is the basis of future academic success (Cahill, 2009). It is seen that handwriting errors in the first grade of primary school are related to academic achievement up to $6^{\text {th }}$ grade (Moore and Rust, 1989).

Therefore, it is essential to develop intervention methods to facilitate the development of graphomotor and skills fine motor of $1^{\text {st }}$ grade children in primary school. In this context, the studies which are already presented intensively in line with the teaching programs in schools may affect their opinions about school due to not taking their developmental level and maturation into account. 
In this study, it is aimed to investigate the effects of physical education based intervention program, which was prepared out of writing activities of children, on fine motor integration, fine motor precision, manual dexterity and upper limb coordination level and indirectly on writing activities of primary school $1^{\text {st }}$ grade children.

\section{Material and Method}

\subsection{Research Model}

Quantitative research model was used in the study. Data for the motor development of the participants were obtained by experimental method in the form of pre-test/post-test.

\subsection{Research Group}

A total of $1231^{\text {st }}$ grade students of a private school with at least 2 years preschool education were included in the study for the sake of implementing the same curriculum in Kütahya province. The classes were randomly assigned to the study and control groups. However, 104 participants (59 experimental group, 45 control group) were evaluated in the experimental dimension of the study according to the attendance record of the children. The mean age of the participants in the experimental group was $6,08 \pm 0,281$ while the mean age of the control group was found to be $6,13 \pm 0,344.53$ of the participants were male and 51 were female.

\subsection{Data Gathering Tools}

The participants' upper limb coordination, manual dexterity, fine motor skill integration and fine motor skill precision levels were analysed using the complete form of The Bruininks-Oseretsky Test of Motor Proficiency Second Edition (BOT-2). Shape Filling-Circle, Shape Filling-Star, Drawing a Line-Crooked, Drawing a LineCurved, Connecting Dots, Paper Folding and Cutting a Circle were applied to determine fine motor skill precision. Circle Copy, Square Copy, Overlapped Circle Copy, Curved Line Copy, Triangle Copy, Diamond Copy, Star Copy, Overlapped Pencils Copy were applied for fine motor skill integration. In order to determine the manual dexterity, the participants were made to put dots in a circle, transfer coins, arrange plastic nails, classify cards and rope blocks. In order to determine the upper limb coordination, ball-release and two-handed catch, two-handed ballcatch, ball-release and one-handed catch, the preferred hand ball-catch, the preferred hand ball-bounce, ball-bounce with two-hand sequence and the preferred hand ball-throw to a target were applied.

The evaluation of the tests was made by 3 referees and the middle value was taken into consideration omitting the highest and the lowest values. The raw values obtained were converted to point scores and the total values of each sub-dimension were determined.

\subsection{Ethical Considerations}

The families of the participants were informed about the current motor development level of the participants and the intervention program and informed consent was obtained.

\subsection{Application Protocol}

Students were divided into specific groups of 20 subjects and were placed in 10 stations, each with 2 students. Considering the age and attention span of the students, each student performed the specified movement for 2 min. at each station. Each station used a different size ball randomly (basketball, volleyball, handball, soccer ball, tennis ball, etc.). Every two minutes, students changed the station in pairs. These 10 stations were carried out 2 rounds. A sample protocol is shown in details in Table 1.

\begin{tabular}{|c|c|c|c|}
\hline Objectives & Acquisition & Training program & Methods \\
\hline $\begin{array}{l}\text {-One-handed and two- } \\
\text { handed ball control } \\
\text { without contacting } \\
\text { the palm } \\
\text { - Controlling moving } \\
\text { ball/objects with } \\
\text { hands and fingers } \\
\text {-Ball orientation with } \\
\text { fingers } \\
\text { - Moving the ball } \\
\text { along the specified } \\
\text { route } \\
\text { - Applying force to } \\
\text { the ball with different } \\
\text { pressures } \\
\text { - Following the ball } \\
\text { with the eye and } \\
\text { moving it in the same } \\
\text { orbit }\end{array}$ & $\begin{array}{l}\text { 1. Can control an } \\
\text { approaching object } \\
\text { with one hand and } \\
\text { two hands. } \\
\text { 2. Can move the } \\
\text { object with right and } \\
\text { left hand where it is } \\
\text { or on a specified } \\
\text { route. } \\
\text { 3. Can move objects } \\
\text { along specified path } \\
\text { using only fingers. } \\
\text { 3. Can apply pressure } \\
\text { to objects at different } \\
\text { rates. } \\
\text { 4. Can repeat the } \\
\text { movement s/ he sees. }\end{array}$ & $\begin{array}{l}\text { Station 1: Balls are thrown into the air with two hands } \\
\text { and caught. } \\
\text { Station } 2 \text { : Balls are thrown into the air with one hand in } \\
\text { turn and captured. } \\
\text { Station 3: The ball is bounced and caught with one } \\
\text { hand and two hands. } \\
\text { Station } 4 \text { : The ball is turned around the head without } \\
\text { contacting the palm. } \\
\text { Station 5: The ball is turned around the waist without } \\
\text { contacting the palm. } \\
\text { Station 6: The ball is rotated with fingers around the } \\
\text { feet on the ground. Rotation is changed once every } 2 \\
\text { turns. } \\
\text { Station 7: The ball is rotated with fingers by drawing } 8 \\
\text { between the feet on the ground. Rotation is changed } \\
\text { once every } 2 \text { turns. } \\
\text { Station } 8: \text { Sitting on the ground, the ball is turned } \\
\text { around the body with fingers without contacting the } \\
\text { palm. } \\
\text { Station 9: Transferring the ball from right to left and } \\
\text { from left to right. In the prone position, arms open on } \\
\text { both sides at chest level, the ball is rolled up to the top } \\
\text { of the head with right hand fingers and carried with left } \\
\text { hand fingers again down to chest level. } \\
\text { Station 10: The ball is squeezed two-handed in opposite } \\
\text { directions without palm contact. }\end{array}$ & $\begin{array}{l}\text { Learning by } \\
\text { doing and } \\
\text { experience, } \\
\text { expression, } \\
\text { demonstration }\end{array}$ \\
\hline
\end{tabular}




\subsection{Statistics}

The quantitative data were evaluated by repeated measure Anova and simple effect test in SPSS 24.0.

\section{Findings}

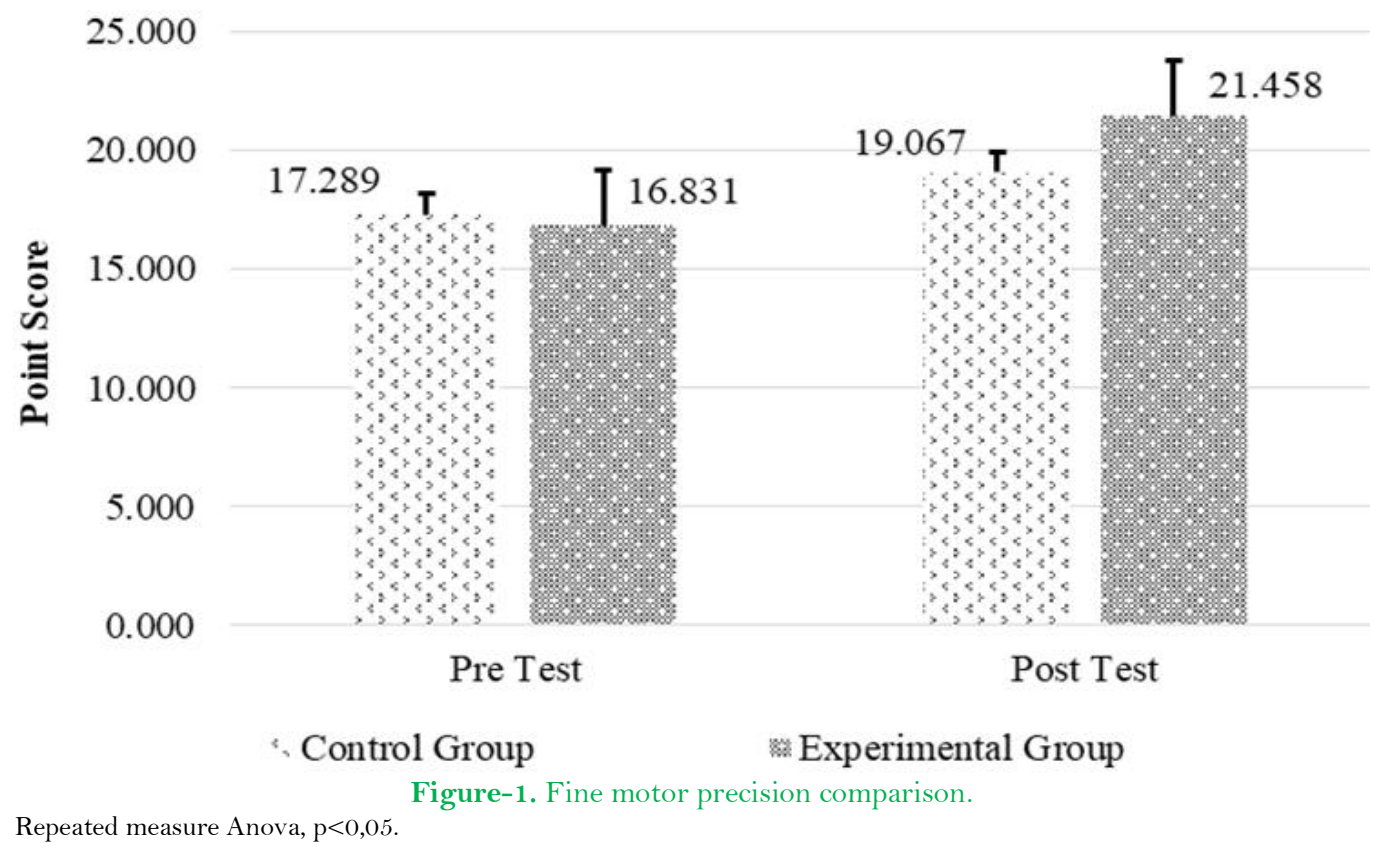

In Figure 1, according to the results of the repeated measurements Anova test, when the change in the group time interaction dimension between the post-test and pre-test of the experimental group and the change between the post-test and the pre-test of the control group were compared, the former was found to be higher than the latter. This difference was statistically significant $\left(\mathrm{F}_{1,102} ; 6.093 ; \mathrm{p}<0,05\right)$.

\begin{tabular}{l|c|c|c|c|c|c}
\hline Groups & $\begin{array}{c}\text { Measurement } \\
(\mathbf{I})\end{array}$ & $\begin{array}{c}\text { Measurement } \\
(\mathbf{J})\end{array}$ & $\begin{array}{c}\text { Mean difference } \\
(\mathbf{I}-\mathbf{J})\end{array}$ & Std. error & F & Sig. \\
\hline Control group & Post test & Pre test & 1.778 & 0.869 & 4.181 & 0.043 \\
\hline Experimental group & Post test & Pre test & 4.627 & 0.759 & 37.136 & 0.000 \\
\hline Simple effect test, $\mathrm{p}<0,05$. &
\end{tabular}

In Table 2, according to the results of the simple effect test, both the change occurring between the post-test and pre-test of the experimental group $\left(\mathrm{F}_{1,102} ; 37.136 ; \mathrm{p}<0,05\right)$ and the change between the post-test and pre-test of the control group $\left(\mathrm{F}_{1,102} ; 4.181 ; \mathrm{p}<0,05\right)$ were found to be statistically significant.

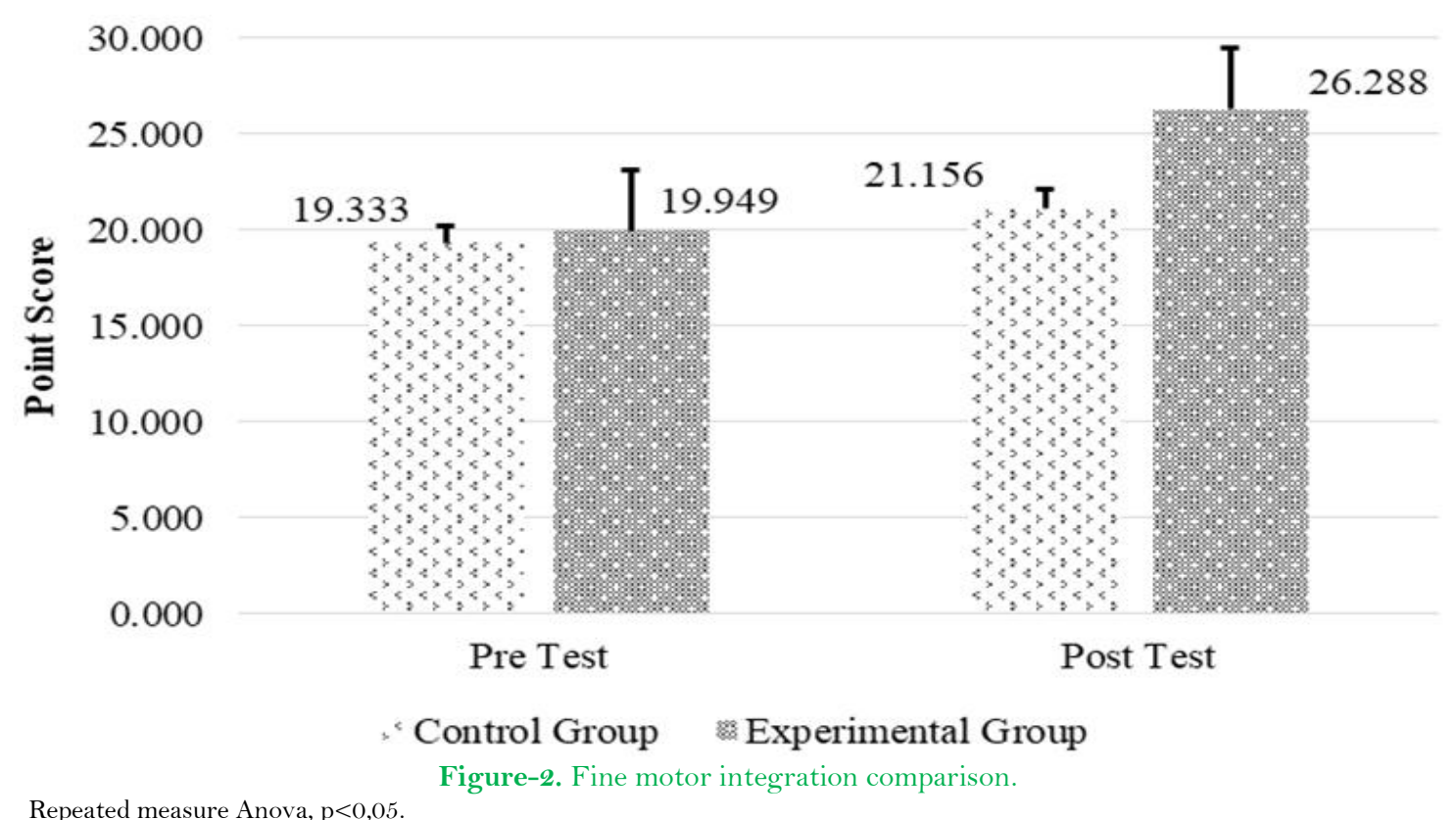

In Figure 2, according to the results of the data analysis, when the change between the post and pre-test values of the experimental group and that of the control were compared, the change in the experimental group was higher than the control group. This difference between two groups was determined to statistically significant. $\left(\mathrm{F}_{1,102} ; 18.460 ; \mathrm{p}<0,05\right)$. 
Table-3. Comparison of fine motor integration measurements in simple effect test.

\begin{tabular}{l|c|c|c|c|c|c}
\multicolumn{6}{c}{ Table-3. Comparison of fine motor integration measurements in simple effect test. } \\
\hline Groups & $\begin{array}{c}\text { Measurement } \\
(\mathbf{I})\end{array}$ & $\begin{array}{c}\text { Measurement } \\
(\mathbf{J})\end{array}$ & $\begin{array}{c}\text { Mean difference } \\
(\mathbf{I}-\mathbf{J})\end{array}$ & Std. error & F & Sig. \\
\hline Control group & Post test & Pre test & 1.822 & 0.792 & 5.296 & $\mathbf{0 . 0 2 3}$ \\
\hline Experimental group & Post test & Pre test & 6.339 & 0.692 & 84.029 & $\mathbf{0 . 0 0 0}$ \\
\hline Simple effect test, $\mathrm{p}<0,05$. &
\end{tabular}

In Table 3, when the results of simple effect test were examined, it was seen that there was a significant difference between the measurements when the change between the post-test and pre-test of the control group was compared $\left(\mathrm{F}_{1,102} ; 5.296 ; \mathrm{p}<0,05\right)$. Similarly, when the change between the post-test and pre-test of the experimental group was compared, a statistically significant difference was found between the measurements $\left(\mathrm{F}_{1,102} ; 84.029\right.$; $\mathrm{p}<0,05)$.

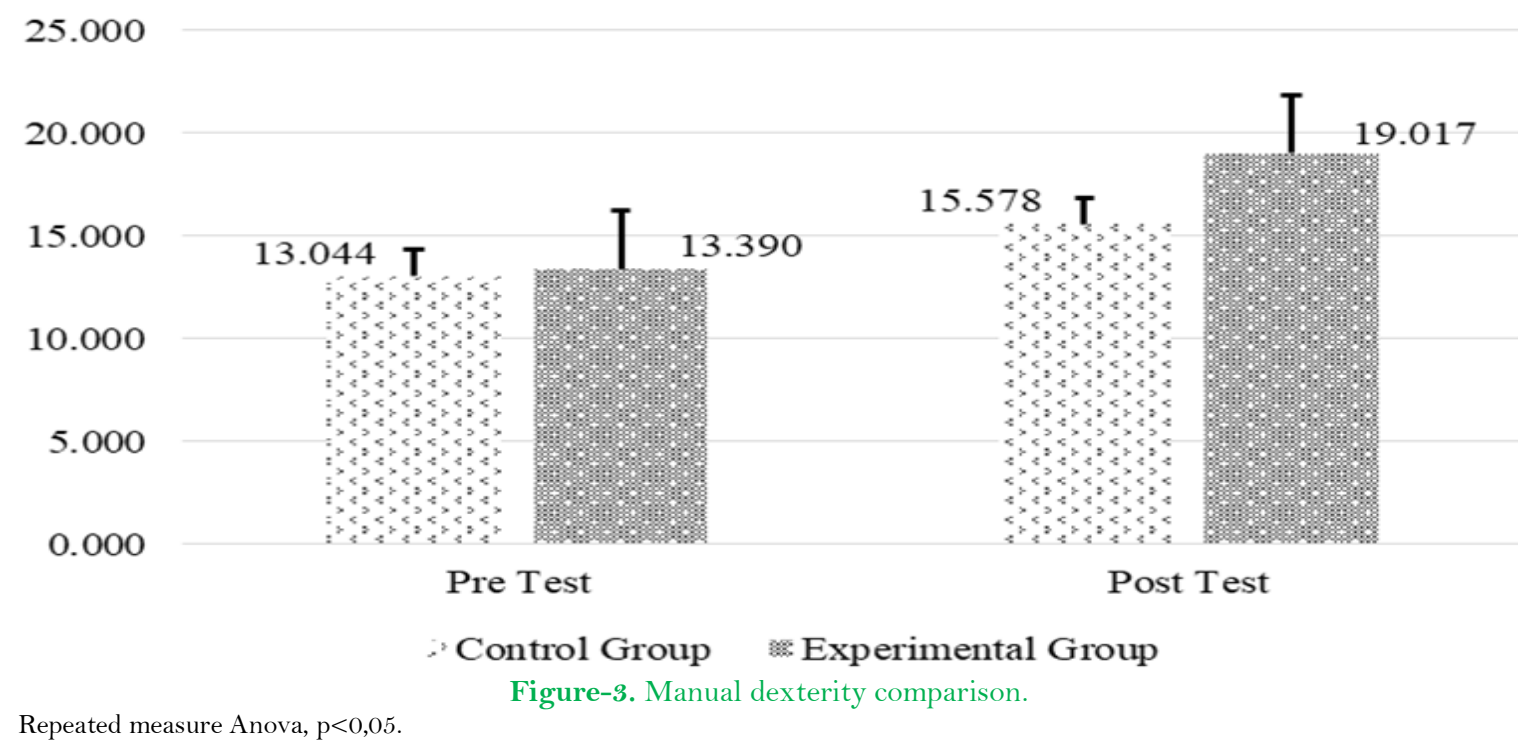

In Figure 3, data analysis results showed that when the change between the pre and post-test values of the experimental group and that of the control were compared, the change was found to be higher in the experimental group than the control group. The differences between the measurements were statistically significant when compared in group dimension $\left(\mathrm{F}_{1,100} ; 17.739 ; \mathrm{p}<0,05\right)$.

\begin{tabular}{l|c|c|c|c|c|c}
\hline \multicolumn{7}{|c|}{ Table-4. Comparison of manual dexterity measurements in simple effect test. } \\
\hline Groups & $\begin{array}{c}\text { Measurement } \\
(\mathbf{I})\end{array}$ & $\begin{array}{c}\text { Measurement } \\
(\mathbf{J})\end{array}$ & $\begin{array}{c}\text { Mean difference } \\
(\mathbf{I}-\mathbf{J})\end{array}$ & Std. error & F & Sig. \\
\hline Control group & Post test & Pre test & 2.533 & 0.553 & 20.966 & 0.000 \\
\hline Experimental group & Post test & Pre test & 5.627 & 0.483 & 135.628 & 0.000 \\
\hline Simple effect test, $\mathrm{p}<0,05$. &
\end{tabular}

In Table 4, when the results of simple effect test were examined, it was seen that there was a significant difference between the measurements when the change between the post-test and pre-test of the control group was compared $\left(\mathrm{F}_{1,102} ; 20.966 ; \mathrm{p}<0,05\right)$. Similarly, when the change between the post-test and pre-test of the experimental group was compared, a statistically significant difference was determined between the measurements $\left(\mathrm{F}_{1,102} ; 135.628 ; \mathrm{p}<0,05\right)$.

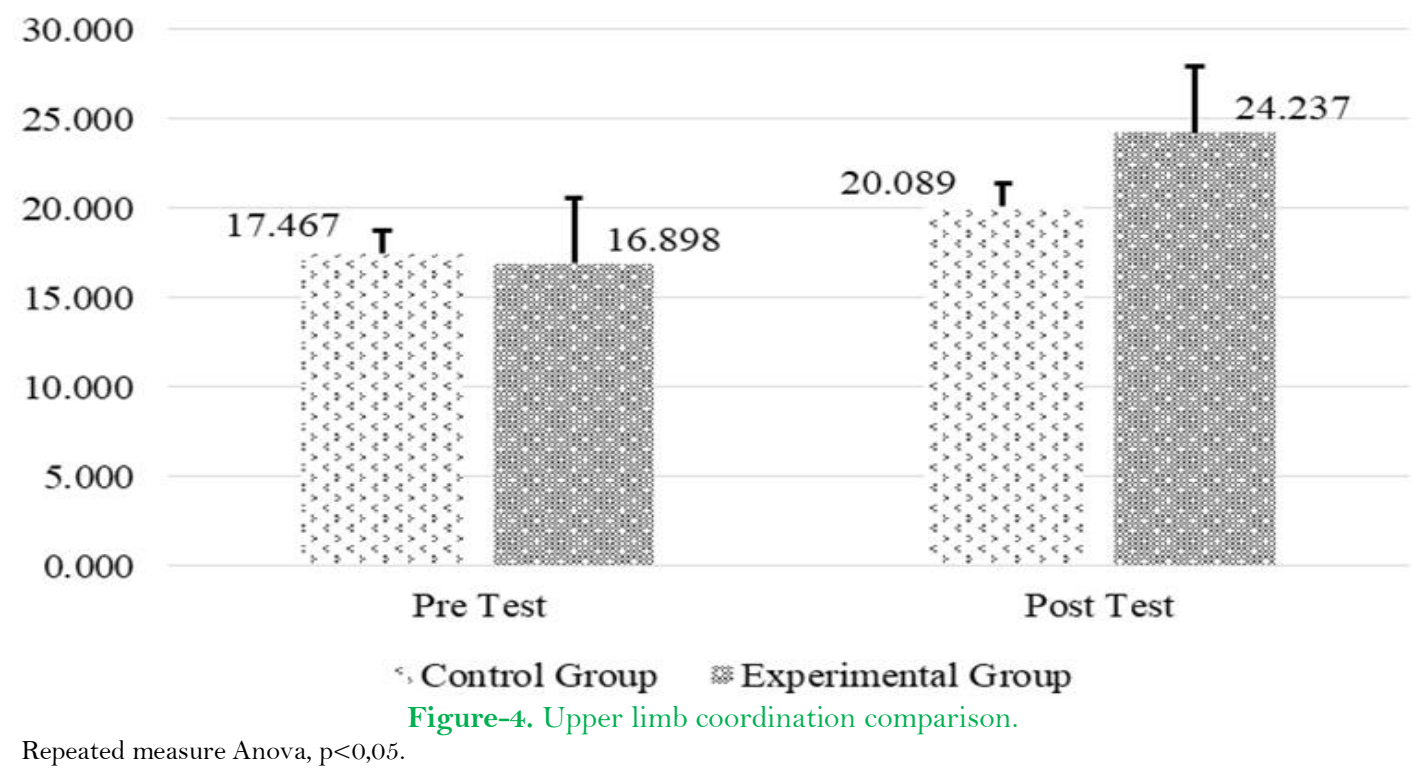

In Figure 4, according to the results of the data analysis, when the improvement between the post and pre-test values of the experimental group and that of the control were compared, the improvement was found to be higher in the experimental group than the control group. This difference between two groups was determined to statistically significant. $\left(\mathrm{F}_{1,102} ; 19.494 ; \mathrm{p}<0,05\right)$. 
Table-5. Comparison of upper limb coordination measurements in simple effect test.

\begin{tabular}{l|c|c|c|c|c|c}
\hline Groups & $\begin{array}{c}\text { Measurement } \\
(\mathbf{I})\end{array}$ & $\begin{array}{c}\text { Measurement } \\
(\mathbf{J})\end{array}$ & $\begin{array}{c}\text { Mean difference } \\
(\mathbf{I}-\mathbf{J})\end{array}$ & Std. error & F & Sig. \\
\hline Control group & Post test & Pre test & 2.622 & 0.805 & 10.620 & $\mathbf{0 . 0 0 2}$ \\
\hline Experimental group & Post test & Pre test & 7.339 & 0.703 & 135.628 & $\mathbf{0 . 0 0 0}$ \\
\hline Simple effect test: $\mathrm{p}<0,05$.
\end{tabular}

In Table 5, according to the results of the simple effect test, both the change occurring between the post-test and pre-test of the experimental group $\left(\mathrm{F}_{1,100} ; 135.628 ; \mathrm{p}<0,05\right)$ and the change between the post-test and pre-test of the control group $\left(\mathrm{F}_{1,102} ; 10.620 ; \mathrm{p}<0,05\right)$ were found to be statistically significant.

\section{Discussion}

It was determined that the manual dexterity level of the children who started primary school grade 1 at an early age was behind that of the older grade 1 students (Kildan and Ahi, 2014). In some studies, visual motor integration came to the fore in individuals who had problems in writing skills, while manual dexterity and upper limb coordination came into prominence in normal writing skills (Tseng and Chow, 2000; Volman et al., 2006). Children with higher scores at standardized visual motor integration tests were shown to produce faster (Tseng and Chow, 2000) and more legible handwriting than those with lower scores (Cornhill and Case-Smith, 1996). In another study, it was found that children with Handwriting problems showed a lack of fine motor control (SmitsEngelsman et al., 2001). In addition, studies on brain function using fMRI revealed a close relationship between visual and motor systems related to handwriting (James, 2010). In addition, a statistically significant relationship between object control skills and visual motor integration was revealed in a study by Du Plessis et al. (2015) investigating the relationship between Grade 1 learners' visual motor integration, visual perception, motor coordination and object control skills. A study examining the effect of fine motor skills on handwriting legibility in preschool age children showed a high level of relationship between fine motor skills and handwriting legibility. The study revealed that the accuracy of hand manipulation skills is factors that influence handwriting legibility (Seo, 2018). While Tseng and Chow (2000) found a high correlation both between writing speed and upper limb coordination and manual dexterity values of normal writing individuals and between writing speed and visual motor integration values in slow writing individuals (Tseng and Chow, 2000). Kaiser et al. (2009) investigated the relationship between visual motor integration, eye-hand coordination and handwriting quality and concluded that the relationship between visual-motor integration and hand-eye coordination can be used to predict the quality of handwriting.

The findings of our study showed that the group who received physical education based intervention program had more improvement in fine motor integration, fine motor precision, manual dexterity and upper limb coordination skills compared to control group.

Kambas et al. (2002) investigated the effect of a motor intervention program emphasizing space and time in children aged 4-5 years. The graphomotor skills of the participants were evaluated with the following BOTMP-CF articles. A significant difference was found between the control and experimental groups after the intervention process. In addition, Spanaki et al. (2008) examined the effect of motor development intervention program on graphomotor, gross and fine skills of children from preschools and primary schools. At the end of the process, regardless of motor competence, the improvements in graphomotor, gross and fine skills were important for all participants. In another study on the effects of intervention program on the development of fine motor and visual motor integration skills in preschool students, the participants in the intervention group showed a statistically significant increase in fine motor and visual motor skills, while the control group showed a slight decrease in both areas (Ohl et al., 2013). The effect of structured handwriting reading program applied to children included in the Head Start program on fine motor skills was examined and the data showed a positive effect on the development of manual skills and fine motor integration in preschool children (Winslow, 2011). In another study, upper limb coordination, manual dexterity, fine motor precision and fine motor integration values were compared in Fine Motor and Early Writing Pre-K Curriculum (FMEW) program applied-experimental group and Handwriting Without Tears - Get Set For School Curriculum (HWT) program applied-experimental group and control group participants. In the study, the participants in the FMEW group achieved the highest score in the sub-tests of fine motor precision, manual dexterity and upper limb coordination (Lear, 2012). In another study on the relationship between handwriting skills and visual motor integration of preschool children, the students who were able to copy the first nine forms in Visual Motor Integration performed significantly better compared to the students who could not copy the first nine VMI forms correctly in both versions of the modified SCRIPT (Daly et al., 2003). In a study by Ratzon et al. (2007) participants in the study group achieved significant gains compared to the control group both in graphomotor test and in the Bruininks-Oseretsky Motor Efficiency Test Long + Form. The study on the effects of short-term graphomotor program aimed at improving writing preparation skills of $1^{\text {st }}$ grade students revealed that motor skill development levels were higher in the intervention group. Jongmans et al. (2003) found that neuromotor task studies gave positive results on handwriting development. Likewise, some studies have shown that visual motor and fine motor intervention programs of occupational treatment are effective in preschool and primary school (Bazyk et al., 2009). In a study investigating the effects of developmental coordination disorder (DCD) motor skills program, significant improvements were observed in hand skills, ball skills and handwriting skills after the training period (Farhat et al., 2016). All these studies support our hypotheses within the scope of our research.

\section{Conclusion}

Many studies have revealed a relationship between fine motor skills and handwriting of children. However, as a result of the pressure exerted on teachers and children who are still in play age due to the academic achievement criteria of the parents, children are subjected to intensive writing education with transition from preschool education to primary school. In fact, this pressure causes children to forget to play during this period and their 
attitudes towards school in the preschool period are negatively affected. Drawing line and similar studies aiming to improve children's writing skills in line with the curriculum can put excessive burden on children depending on their maturation and readiness levels. This may have a negative impact on the future perspective of education of children who will be in education for long periods of time according to the education system of the country in which they live. In informal interviews with $1^{\text {st }}$ grade students and their parents, they stated that children liked kindergarten more than primary school and they got very tired during writing drills. On the other hand, it was determined that the students in the intervention program group had no negative thoughts about the school. It can be thought that this may be due to transferring the children's concentration away from play on writing skills.

For this reason, it can be stated that intervention programs developed based on physical education can positively affect children's fine motor skills development and indirectly writing skills. In this regard, physical education-based programs for fine motor skills development can be added to the primary school grade 1 curriculum. In addition, it is important to conduct a qualitative research in order to reveal the reasons of the negative thoughts that the children have developed against school and to eliminate these negative factors.

\section{References}

Adams, B.J., F. Margaron and B.J. Kaplan, 2012. Comparing video games and laparoscopic simulators in the development of laparoscopic skills in surgical residents. Journal of Surgical Education, 69(6): 714-717.Available at: http://dx.doi.org/10.1016/j.jsurg.2012.06.006.

Alston, J. and J. Taylor, 1987. Handwriting: Theory, research, and practice. New York: Croom Helm.

Bart, O., D. Hajami and Y. Bar-Haim, 2007. Predicting school adjustment from motor abilities in kindergarten. Infant and Child Development: An International Journal of Research and Practice, 16(6): 597-615.Available at: https://doi.org/10.1002/icd.5 14.

Bazyk, S., P. Michaud, G. Goodman, P. Papp, E. Hawkins and M.A. Welch, 2009. Integrating occupational therapy services in a kindergarten curriculum: A look at the outcomes. American Journal of Occupational Therapy, 63(2): 160-171.Available at: https://doi.org/10.5014/ajot.63.2.160.

Beery, K.E., 1997. The Beery-Buktenica developmental test of visual-motor integration (4th Edn.). Parsippany, NJ: Modern Curriculum Press.

Berninger, V.W., 2009. Highlights of programmatic, interdisciplinary research on writing. Learning Disabilities Research \& Practice, 24(2): 69-80.Available at: https://doi.org/10.1111/j.1540-5826.2009.00281.x.

Bingham, G.P. and W. Snapp-Childs, 2019. Training children aged 5-10 years in manual compliance control to improve drawing and handwriting. Human Movement Science, 65: 42-50.Available at: https://doi.org/10.1016/j.humov.2018.04.002.

Cahill, S.M., 2009. Where does handwriting fit in? Strategies to support academic achievement. Intervention in School and Clinic, 44(4): 223228.Available at: https://doi.org/10.1177/1053451208328826.

Cameron, C.E., L.L. Brock, W.M. Murrah, L.H. Bell, S.L. Worzalla, D. Grissmer and F.J. Morrison, 2012. Fine motor skills and executive function both contribute to kindergarten achievement. Child Development, 83(4): 1229-1244.Available at: https://doi.org/10.1111/j.1467-8624.2012.01768.x.

Coll, C.G., 2015. Editorial: Continuity and change in child development. Child Development, 86(1): 7-9.Available at: http://dx.doi.org/10.1111/cdev.12353.

Cornhill, H. and J. Case-Smith, 1996. Factors that relate to good and poor handwriting. American Journal of Occupational Therapy, 50(9): 732-739.Available at: https://doi.org/10.5014/ajot.50.9.732.

Daly, C.J., G.T. Kelley and A. Krauss, 2003. Relationship between visual-motor integration and handwriting skills of children in kindergarten: A modified replication study. American Journal of Occupational Therapy, 57(4): 459-462.Available at: https://doi.org/10.5014/ajot.57.4.459.

Di Brina, C., R. Niels, A. Overvelde, G. Levi and W. Hulstijn, 2008. Dynamic time warping: A new method in the study of poor handwriting. Human Movement Science, 27(2): 242-255.

Du Plessis, W., D. Coetzee and A.E. Pienaar, 2015. Interrelationships between visual-motor integration, visual perception, motor coordination and object control skills of grade 1-learners: NW-child study. South African Journal for Research in Sport, Physical Education and Recreation, 37(3): 69-81.

Farhat, F., I. Hsairi, H. Baati, B. Smits-Engelsman, K. Masmoudi, R. Mchirgui, C. Triki and W. Moalla, 2016. The effect of a motor skills training program in the improvement of practiced and non-practiced tasks performance in children with developmental coordination disorder (DCD). Human Movement Science, 46: 10-22.Available at: https://doi.org/10.1016/j.humov.2015.12.001.

Feder, K., A. Majnemer and A. Synnes, 2000. Handwriting: Current trends in occupational therapy practice. Canadian Journal of Occupational Therapy, 67(3): 197-204.Available at: https://doi.org/10.1177/000841740006700313.

Feder, K.P. and A. Majnemer, 2007. Handwriting development, competency, and intervention. Developmental Medicine \& Child Neurology, 49(4): 312-317.Available at: https://doi.org/10.1111/j.1469-8749.2007.00312.x.

Gallahue, D., J. Ozmun and J.D. Goodway, 2012. Understanding motor development: Infants, children, adolescents, adults. 7 th Edn., New York: Mc Graw Hill.

Gaul, D. and J. Issartel, 2016. Fine motor skill proficiency in typically developing children: On or off the maturation track? Human Movement Science, 46: 78-85.Available at: https://doi.org/10.1016/j.humov.2015.12.011.

James, K.H., 2010. Sensori-motor experience leads to changes in visual processing in the developing brain. Developmental science, 13(2): 279-288.Available at: https://doi.org/10.1111/j.1467-7687.2009.00883.x.

Jongmans, M.J., B.C. Smits-Engelsman and M.M. Schoemaker, 2003. Consequences of comorbidity of developmental coordination disorders and learning disabilities for severity and pattern of perceptual-motor dysfunction. Journal of Learning Disabilities, 36(6): 528537.Available at: https://doi.org/10.1177/00222194030360060401.

Kaiser, M.-L., J.-M. Albaret and P.-A. Doudin, 2009. Relationship between visual-motor integration, eye-hand coordination, and quality of handwriting. Journal of Occupational Therapy, Schools, \& Early Intervention, 2(2): 87-95.Available at: https://doi.org/10.1080/19411240903146228.

Kambas, A., K. Amoutzas, H. Makri, V. Gourgoulis and P. Antoniou, 2002. The effect of psychomotor education emphasizing in time and space, on the development of graphomotor skills in preschoolers. Exercise and Society, 32(2): 49-57.

Kildan, A.O. and B. Ahi, 2014. Evaluation of the adaptation of 66-72 month old children to primary schools in Turkey. Procedia-Social and Behavioral Sciences, 116: 2417-2423.Available at: https://doi.org/10.1016/j.sbspro.2014.01.585.

Lam, S.S., R.K. Au, H.W. Leung and C.W. Li-Tsang, 2011. Chinese handwriting performance of primary school children with dyslexia. Research in Developmental Disabilities, 32(5): 1745-1756.Available at: https://doi.org/10.1016/j.ridd.2011.03.001.

Lamme, L.L., 1979. Handwriting: In an early childhood curriculum. Young Children, 35(1): 20-27.

Lauricella, A.R., E. Wartella and V.J. Rideout, 2015 . Young children's screen time: The complex role of parent and child factors. Journal of Applied Developmental Psychology, 36: 11-17.Available at: https://doi.org/10.1016/j.appdev.2014.12.001.

Lear, W.S., 2012. Carry-over effect of a handwriting readiness program on handwriting-related skills of children the year following intervention. Master's Thesis. Eart Carolina University.

Levine, M.D., 1987. Development variation and learning disorders. Cambridge, MA: Educators Publishing Service, Inc.

Linde, V.D.B.W., J.J. Van Netten, E. Otten, K. Postema, R.H. Geuze and M.M. Schoemaker, 2013. A systematic review of instruments for assessment of capacity in activities of daily living in children with developmental co-ordination disorder. Child: Care. Health and Development, 41(1): 1-12.Available at: http://dx.doi.org/10.1111/cch.12124.

Maeland, A.F., 1992. Handwriting and perceptual-motor skills in clumsy, dysgraphic, and 'normal'children. Perceptual and Motor Skills, 75(3_suppl): 1207-1217.Available at: https://doi.org/10.2466/pms.75.8.1207-1217. 
Magalhaes, L., A. Cardoso and C. Missiuna, 2011. Activities and participation in children with developmental coordination disorder: A systematic review. Research in Developmental Disabilities, 32(4): 1309-1316.Available at: https://doi.org/10.1016/j.ridd.2011.01.029.

Maitland, C., G. Stratton, S. Foster, R. Braham and M. Rosenberg, 2013. A place for play? The influence of the home physical environment on children's physical activity and sedentary behaviour. International Journal of Behavioral Nutrition and Physical Activity, 10(99): 1-21.Available at: http://dx.doi.org/10.1186/1479-5868-10-99.

Marr, D., S. Cermak, E.S. Cohn and A. Henderson, 2003. Fine motor activities in head start and kindergarten classrooms. American Journal of Occupational Therapy, 57(5): 550-557.Available at: https://doi.org/10.5014/ajot.57.5.550.

McHale, K. and S.A. Cermak, 1992. Fine motor activities in elementary school: Preliminary findings and provisional implications for children with fine motor problems. American Journal of Occupational Therapy, 46(10): 898-903.Available at: https://doi.org/10.5014/ajot.46.10.898.

Moore, R.L. and J.O. Rust, 1989. Printing errors in the prediction of academic performance. Journal of School Psychology, 27(3): 297300.Available at: https://doi.org/10.1016/0022-4405(89)90044-7.

Ohl, A.M., H. Graze, K. Weber, S. Kenny, C. Salvatore and S. Wagreich, 2013. Effectiveness of a 10-week Tier-1 Response to Intervention program in improving fine motor and visual-motor skills in general education kindergarten students. American Journal of Occupational Therapy, 67(5): 507-514.Available at: https://doi.org/10.5014/ajot.2013.008110.

Ratzon, N.Z., D. Efraim and O. Bart, 2007. A short-term graphomotor program for improving writing readiness skills of first-grade students. American Journal of Occupational Therapy, 61(4): 399-405.Available at: https://doi.org/10.5014/ajot.61.4.399.

Rosenblum, S., S. Parush and P.L. Weiss, 2003. Computerized temporal handwriting characteristics of proficient and non-proficient handwriters. American Journal of Occupational Therapy, 57(2): 129-138.Available at: https://doi.org/10.5014/ajot.57.2.129.

Seo, S.-M., 2018. The effect of fine motor skills on handwriting legibility in preschool age children. Journal of Physical Therapy Science, 30(2): 324-327.Available at: https://doi.org/10.1589/jpts.30.324.

Shams, L. and R. Kim, 2010. Bayesian priors and multisensory integration at multiple levels of visual processing: Reply to comments on "crossmodal influences on visual perception". Physics of Life Reviews, 7(3): 295-298.Available at: https://doi.org/10.1016/j.plrev.2010.07.006.

Smits-Engelsman, B.C., A.S. Niemeijer and G.P. van Galen, 2001. Fine motor deficiencies in children diagnosed as DCD based on poor grapho-motor ability. Human Movement Science, 20(1-2): 161-182.Available at: https://doi.org/10.1016/s0167-9457(01)00033-1.

Smits, E.J., A.J. Tolonen, L. Cluitmans, M. van Gils, R.C. Zietsma, M.A. Tijssen and N.M. Maurits, 2018. Reproducibility of standardized fine motor control tasks and age effects in healthy adults. Measurement, 114: 177-184.Available at: https://doi.org/10.1016/j.measurement.2017.09.011.

Spanaki, I., A. Nikolopoulos, E. Skordilis and D. Koutsouki, 2008. Motor and graphomotor performance of students aged from 5 to 10 years old. European Psychomotricity Journal, 1(2): 38 - 45

Stevenson, N.C. and C. Just, 2014. In early education, why teach handwriting before keyboarding? Early Childhood Education Journal, 42(1): 49-56.Available at: https://doi.org/10.1007/s10643-012-0565-2.

Suggate, S., E. Pufke and H. Stoeger, 2019. Children's fine motor skills in kindergarten predict reading in grade 1. Early Childhood Research Quarterly, 47: 248-258.Available at: https://doi.org/10.1016/j.ecresq.2018.12.015.

Tseng, M.H. and S.A. Cermak, 1993. The influence of ergonomic factors and perceptual-motor abilities on handwriting performance. American Journal of Occupational Therapy, 47(10): 919-926.Available at: https://doi.org/10.5014/ajot.47.10.919.

Tseng, M.H. and S.M. Chow, 2000. Perceptual-motor function of school-age children with slow handwriting speed. American Journal of Occupational Therapy, 54(1): 83-88.Available at: https://doi.org/10.5014/ajot.54.1.83.

Volman, M., B.M. Van Schendel and M.J. Jongmans, 2006. Handwriting difficulties in primary school children: A search for underlying mechanisms. American Journal of Occupational Therapy, 60(4): 451-460.Available at: https://doi.org/10.5014/ajot.60.4.451.

Wang, T.N., M.H. Tseng, B.N. Wilson and F.C. Hu, 2009. Functional performance of children with developmental coordination disorder at home and at school. Developmental Medicine \& Child Neurology, 51(10): 817-825.Available at: https://doi.org/10.1111/j.14698749.2009.03271.x.

Wilhelm, I., A. Prehn-Kristensen and J. Born, 2012. Sleep-dependent memory consolidation-what can be learnt from children? Neuroscience \& Biobehavioral Reviews, 36(7): 1718-1728.Available at: https://doi.org/10.1016/j.neubiorev.2012.03.002.

Winslow, B., 2011. Effects of a structured handwriting readiness program on the fine motor skills of children in head start. Master's Thesis. Eart Carolina University. 